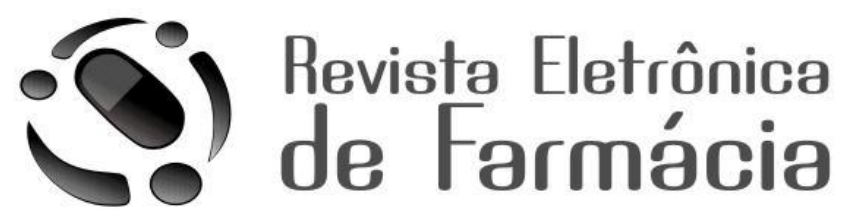

REF - ISSN 1808-0804 Vol. X (2), 01 - 23, 2013.

\title{
ADEQUAÇÃo DE PROTOCOLOS DE BIOSSEGURANÇA EM FARMÁCIA DE MANIPULAÇÃO DO INTERIOR DA BAHIA COM BASE NA RDC 67/2007
}

ADEQUACY OF BIOSAFETY PROTOCOLS IN A COMPOUNDING PHARMACY IN THE CITY OF BAHIA BASED TO RDC 67/2007

IDONEIDAD DE LOS PROTOCOLOS DE SEGURIDAD DE LA BIOTECNOLOGÍA EN LA FARMACIADE MANEJO DEL INTERIOR DE LA BAHIA BASADOS EN RDC 67/2007

\footnotetext{
${ }^{1 *}$ Francine Cristina Silva, ${ }^{1}$ Luciano Pereira Rosa, ${ }^{2}$ Marisol Porto Rocha, ${ }^{1}$ Mateus Freire Leite
}
${ }^{1}$ Universidade Federal da Bahia, Instituto Multidisciplinar em Saúde, Campus Anísio Teixeira.
${ }^{2}$ Farmacêutica graduada na Universidade Federal da Bahia, Instituto Multidisciplinar em Saúde, Campus Anísio Teixeira.

*autor para correspondência: drfransilva@yahoo.com.br

Recebido em 22/05/2012, Aceito em 28/06/2013

\section{RESUMO}

A farmácia magistral sofreu uma grande evolução nos últimos anos, porém esse 
Silva, F.C.; Rosa, L.P.; Rocha, M.P.; Leite, M.F. Revista Eletrônica de Farmácia Vol. X (2), $01-23,2013$.

crescimento não foi proporcional a melhoria nas condições ambientais e de trabalho. A complexidade no ambiente de trabalho cresceu com as novas exigências da Resolução da Diretoria colegiada no 67 de 2007(RDC 67). Os riscos ocupacionais, nesse contexto, também se tornaram mais evidentes, o que torna de extrema importância analisá-lo por meio de técnicas de análise de riscos. Tomando como foco umafarmácia de manipulação de uma cidade do interior da Bahia, foi realizado um levantamento dos riscos e realizado o diagnostico situacional com base na RDC 67/2007, normas regulamentadoras de saúde do trabalho (NR's) e normas da ABNT. Posteriormente foram propostas possíveis adequações para cada situação de risco identificada. Os resultados mostraram a necessidade de adequações tanto de ordem estrutural na empresa como pequenas adequações simples e de baixo custo que podem minimizar sérios riscos ocupacionais, especialmente ações preventivas e ações diretas sobre a fonte de risco.

Palavras-chave: saúde do trabalhador, riscos ocupacionais, segurança

\section{ABSTRACT}

The masterful pharmacy had been many developments in recent years, but this growth was not proportional to improvement in environmental conditions and work. The complexity in the workplace has grown with the new requirements of Board Resolution No. 67 of 2007 (RDC 67), which reflected in aspects related to occupational hazards. Occupation risks becoming more apparent, so the improvement of analytical techniques by different types of risks in these environments are needed. Taking as its focus a pharmacy in the city of Bahia, was a survey of the risks and made the diagnosis with situational based on the RDC 67/2007, regulating occupational health standards (NR's) and Brazilian Association of Technical Standards (ABNT). Based on the results were suggested preventive actions for each risk identified. The results showed that structural adjustments are needed, both in company structure as small and low adjustments, which can minimize serious occupational hazards, especially preventive measures and actions on the direct source of risk.

Keywords: occupational health, occupational risks, safety

\section{RESUMEN}

La farmacia de enseñanza se ha avanzado mucho em los últimos años, pero este crecimiento no fue proporcional a lamejora de las condiciones ambientales y de trabajo. La complejidad em el lugar de trabajo ha crecido com lãs nuevas exigencias de La Resolución Del Directorio N $\circ 67$ de 2007 (RDC 67). Los riesgos laboral es en este contexto, también se hacen más evidentes, lo que hace que sea muy importante analizar lo a través de técnicas de análisis de riesgos. Centrándose en una farmácia em um pueblo em Bahía, se realizó una encuesta de los riesgos e hizo el diagnóstico de La 
Silva, F.C.; Rosa, L.P.; Rocha, M.P.; Leite, M.F. Revista Eletrônica de Farmácia Vol. X (2), $01-23,2013$.

situación sobre la base de RDC 67/2007, que regula las normas de salud ocupacional (NR) y las normas de la ABNT. Más tarde, lãs propuesta seran posibles ajustes para cada riesgo identificado. Los resultados mostraron La necesidad de ajustes estructurales tanto de La compañía como pequeños ajustes simples y de bajo costo que puede reduciral mínimo los riesgos laborales graves, en especial las acciones preventivas y acciones directas sobre la fuente de riesgo.

Palabras clave: salud laboral, riesgos laborales, seguridad

\section{INTRODUÇÃO}

A farmácia de manipulação, também conhecida como magistral, é o estabelecimento de saúde onde os medicamentos são preparados um a um, por farmacêuticos e auxiliares, mediante a solicitação de um cliente portador de uma receita médica, veterinária ou odontológica. Os laboratórios das farmácias de manipulação preparam desde florais de Bach até anticonvulsivos e hormônios( $\left.{ }^{1}\right)$.

A Agência Nacional de Vigilância Sanitária (ANVISA) regulamenta o funcionamento das farmácias magistrais com o objetivo de garantir a qualidade e segurança dos medicamentos manipulados. A Resolução RDC $n^{\circ}$ $67 / 2007\left({ }^{2}\right)$ fixa os requisitos mínimos para manipulação de medicamentos, abrangendo questões relacionadas a instalações, equipamentos, recursos humanos, aquisição e controle de qualidade da matéria-prima. Determina, também, as exigências para armazenamento, avaliação farmacêutica da prescrição, fracionamento, conservação, transporte, dispensação das formulações e atenção farmacêutica aos usuários. Além destes itens, esta RDC abrange também várias estratégias de minimização de riscos ocupacionais inerentes a todas as atividades desenvolvidas no estabelecimento como o Programa de Controle Médico de Saúde Ocupacional (PCMSO) a todos os funcionários diretamente envolvidos na manipulação de substâncias e produtos de alto risco e a exigência de adequação da empresa às normas regulamentadoras de saúde do trabalho (NRs). Além do uso de equipamentos de proteção individual apropriados, condizentes com os riscos, os controles e o volume de trabalho, visando proteção e segurança dos manipuladores $\left({ }^{2,3}\right)$. Tendo em vista os diferentes riscos presentes neste ambiente, as farmácias de manipulação, apesar de constituírem unidades de pequeno porte, apresentam situações não menos preocupantes no que tange a riscos ocupacionais do que as de produção de medicamentos em grande escala. Segundo Borges e Ribeiro $\left({ }^{1}\right)$, apesar da evolução da legislação voltada à segurança ocupacional em farmácias magistrais, os acidentes de trabalho ainda persistem no setor e esse fato muito se deve a 
Silva, F.C.; Rosa, L.P.; Rocha, M.P.; Leite, M.F. Revista Eletrônica de Farmácia Vol. X (2), $01-23,2013$.

dificuldade de conseguir profissionais qualificados e o pouco investimento destinado a prevenção e segurança no trabalho.

O impacto dos acidentes de trabalho é evidenciado por dados estatísticos do Instituto Nacional do Seguro Social (INSS) que registrou 653 mil acidentes de trabalho, número $27,5 \%$ maior que em 2006. Esse número reflete um impacto considerável dos acidentes de trabalho na economia do país, representando $2,5 \%$ do Produto Interno Bruto (PIB). No período dos anos de 1997 a 2005, foram registrados 491.711 acidentes de trabalho. As empresas especializadas na fabricação de produtos farmacoquímicos contribuíram com um total de 125 acidentes e as especializadas na fabricação de medicamentos para uso humano, com 962 acidentes de trabalho, dos casos registrados, embora se acredite que os números sejam maiores devido aos casos não registrados $\left({ }^{4}\right)$.

O alto índice de acidentes de trabalho no setor farmacoquímico justifica a importância do presente estudo. As atividades desenvolvidas nesse local expõem constantemente os funcionários a riscos químicos, através da manipulação de produtos químicos perigosos como também riscos físicos, biológicos e ergonômicos. Os riscos ocupacionais, nesse contexto, também são evidentes, o que torna de extrema importância o objetivo deste trabalho, que consiste em diagnosticar os principais riscos químicos, físicos, biológicos e ergonômicos nos diferentes setores de uma farmácia de manipulação do interior da Bahia e, com base na RDC 67 de 2007, implementar medidas para minimização de eventuais riscos ocupacionais aos quais os trabalhadores da Empresa possam estar expostos e auxiliar a mesma nas adequações tanto de ordem estrutural como pequenas adequações simples e de baixo custo que podem minimizar sérios riscos ocupacionais. Os dados obtidos neste estudo, uma vez divulgados, poderão ainda auxiliar outras empresas no setor, provendo $\mathrm{o}$ processo produtivo e $\mathrm{o}$ ambiente de trabalho mais seguro e, por consequência mais eficiente.

\section{MATERIAL E MÉTODOS}

O presente estudo foi planejado para beneficiar as condições de saúde dos trabalhadores de uma Empresa, de acordo com uma das propostas do Edital do "Programa de Iniciação Científica e Tecnológica para Micro e Pequenas Empresas (BITEC) do Instituto Edvaldo Lodi (IEL) do Estado da Bahia", que contemplou com apoio financeiro a realização dessa proposta.

\section{LOCAL DE PESQUISA}

A Farmácia que foi estudada é de "médio porte", segundo a classificação do SEBRAE para Micro e Pequenas Empresas que considera 
Silva, F.C.; Rosa, L.P.; Rocha, M.P.; Leite, M.F. Revista Eletrônica de Farmácia Vol. X (2), $01-23,2013$.

empresa de médio porte no setor de Comércio e Serviços àquelas com um quadro de funcionários que compreende de 50 a 99 empregados $\left({ }^{5}\right)$. Para 0 desenvolvimento das atividades na empresa os funcionários trabalham em dois turnos de quatro horas cada, de segunda-feira a sexta-feira, e um turno aos sábados, sem utilização de horas extras. Tem como atividade principal a fabricação de medicamentos para uso humano que, segundo a Classificação Nacional de Atividades Econômicas (CNAE), é tida como de grau de risco $3\left({ }^{6}\right)$ e trabalha com antibióticos, hormônios, citostáticos, medicamentos controlados, medicamentos homeopáticos, medicamentos fitoterápicos, florais, dermocosméticos e nutracêuticos. Suas instalações constam de uma recepção, um laboratório de sólidos, um laboratório de semi-sólidos, um laboratório de controle de qualidade, uma sala de lavagem, um almoxarifado de matérias-primas, uma sala de administração, uma copa e DML (depósito de materiais de limpeza).

\section{DIAGNÓSTICO DOS RISCOS}

Para realização do estudo, primeiramente foi realizado um levantamento bibliográfico nas bases de dados Scielo, Lillacs, Bireme, manuais institucionais e legislação pertinente para capacitação e elaboração de um barema ou "checklist' contendo os aspectos de maior relevância observados a respeito de cada um dos tipos de riscos. O material elaborado foi utilizado como ferramenta para auxiliar na evidenciação dos riscos físicos, químicos, biológicos e ergonômicos evidentes nos diferentes setores da farmácia magistral estudada, por meio de visitas previamente programadas, registros fotográficos e coleta de informações como visualizado nos quadros 1 , 2 e 3 :

Quadro 1: Checklist para avaliação de riscos físicos em farmácia magistral.

\begin{tabular}{||l|l||}
\hline \multicolumn{2}{|l|}{ Barema para riscos físicos } \\
\hline 1 & Existe equipamento de proteção contra incêndio e sinalização pertinente? \\
\hline 2 & Existem parapeitos devidamente sinalizados? \\
\hline 3 & $\begin{array}{l}\text { As escadas possuem corrimão e iluminação suficiente? Degraus e piso estão } \\
\text { apropriados com material antiderrapante? }\end{array}$ \\
\hline 4 & Existem equipamentos elétricos com sinalização para choque elétrico? \\
\hline 5 & $\begin{array}{l}\text { Existe POP (Procedimento operacional padrão) para acidentes com vidrarias } \\
\text { quebradas facilmente acessíveis? }\end{array}$ \\
\hline 6 & $\begin{array}{l}\text { Existem saídas de emergência e rota de fuga sinalizada em todos os setores? } \\
\text { (Segundo a NR-23) }\end{array}$ \\
\hline 7 & As Tomadas possuem sinalização de voltagem? \\
\hline
\end{tabular}


Silva, F.C.; Rosa, L.P.; Rocha, M.P.; Leite, M.F. Revista Eletrônica de Farmácia Vol. X (2), $01-23,2013$.

\begin{tabular}{|l|l|l|}
\hline 8 & Todos os setores possuem iluminação e ventilação adequada? \\
\hline 9 & As portas com retorno automático possuem sinalização? \\
\hline 10 & Os materiais de limpeza estão guardados unicamente no DML? \\
\hline 11 & Todos os degraus presente na farmácia são identificados? \\
\hline 12 & Falta de sinalização de alta tensão nas caixas de disjuntores \\
\hline 13 & O teto possui vedação adequada segundo a RDC $67 / 2007 ?$ \\
\hline 14 & $\begin{array}{l}\text { Existem dificuldades de trânsito de pessoas com risco de choques entre as mesmas } \\
\text { e/ou equipamentos e/ou móveis em algum setor da empresa? Se positivo, quais? }\end{array}$ \\
\hline 15 & Existem equipamentos que emitem grande quantidade de calor sem sinalização? \\
\hline 16 & Existe a mensuração dos ruídos dos equipamentos da empresa? \\
\hline
\end{tabular}

Quadro 2: Checklist para avaliação de riscos químicos em farmácia magistral.

\begin{tabular}{|c|c|}
\hline \multicolumn{2}{|c|}{ Barema para riscos químicos } \\
\hline 1 & $\begin{array}{l}\text { Os produtos do almoxarifado trazem o diagrama de Hommel ou rotulagem } \\
\text { equivalente? }\end{array}$ \\
\hline 2 & Existe controle da entrada e saída de substâncias? \\
\hline 3 & $\begin{array}{l}\text { As substâncias são armazenadas em locais destinados exclusivamente a produtos } \\
\text { químicos, isto é, não são armazenados juntos alimentos, equipamentos, roupas e } \\
\text { outros tipos de objetos? }\end{array}$ \\
\hline 4 & $\begin{array}{l}\text { O(s)responsável(is) pelo almoxarifado recebeu(ram) capacitação para esta } \\
\text { atividade? Existe registro? }\end{array}$ \\
\hline 5 & $\begin{array}{l}\text { O local está sinalizado, isto é, existe uma indicação de que lá estão armazenadas } \\
\text { substâncias químicas? }\end{array}$ \\
\hline 6 & O local possui pelo menos duas saídas? \\
\hline 7 & $\begin{array}{l}\text { Existe espaço entre as prateleiras de forma que quando for necessário pegar um } \\
\text { frasco de produto, isto possa ser feito com segurança? }\end{array}$ \\
\hline 8 & $\begin{array}{l}\text { Existem equipamentos de proteção individual (EPI) e equipamentos de proteção } \\
\text { coletiva (EPC) próximo ao almoxarifado para casos de emergência? }\end{array}$ \\
\hline 9 & Existe extintor de incêndio em local de fácil acesso? \\
\hline 10 & $\begin{array}{l}\text { Existem números de telefones de emergência afixados em local visível, próximo ao } \\
\text { telefone do local de trabalho? }\end{array}$ \\
\hline 11 & $\begin{array}{l}\text { Os produtos que podem reagir violentamente entre si, isto é são incompatíveis, } \\
\text { estão armazenados separadamente? }\end{array}$ \\
\hline 12 & Os líquidos estão armazenados nas prateleiras inferiores? \\
\hline 13 & $\begin{array}{l}\text { Nas prateleiras existe espaço suficiente para que os produtos não fiquem } \\
\text { amontoados? }\end{array}$ \\
\hline
\end{tabular}


Silva, F.C.; Rosa, L.P.; Rocha, M.P.; Leite, M.F. Revista Eletrônica de Farmácia Vol. X (2), $01-23,2013$.

\begin{tabular}{|c|c|}
\hline 14 & As prateleiras estão livres de frascos vazios? \\
\hline 15 & As prateleiras do almoxarifado são firmes? \\
\hline 16 & Essas prateleiras são resistentes também ao ataque do próprio produto? \\
\hline 17 & $\begin{array}{l}\text { Os frascos ou recipientes estão em bom estado de conservação, sem danificações, } \\
\text { ferrugens ou rótulos sujos ou rasgados? }\end{array}$ \\
\hline 18 & Todos os frascos ou recipientes estão bem fechados? \\
\hline 19 & Existem datas de fabricação e validade nos rótulos dos produtos? \\
\hline 20 & Todos os rótulos estão limpos, legíveis e isentos de poeira ou contaminação? \\
\hline 21 & $\begin{array}{l}\text { As FISPQ (Ficha de Informação de Segurança de Produto Químico) estão } \\
\text { facilmente disponíveis? }\end{array}$ \\
\hline 22 & As FISPQ são redigidas em linguagem compreensível aos trabalhadores? \\
\hline 23 & $\begin{array}{l}\text { Asinalização do local esta sendo eficiente para comunicar a informação (está em } \\
\text { local visível, em boas condições de leitura, é trocada periodicamente para chamar } \\
\text { a atenção)? }\end{array}$ \\
\hline 24 & $\begin{array}{l}\text { Os corredores, as saídas e outras passagens estão desobstruídas de modo a } \\
\text { facilitar a fuga ou a entrada de equipes de socorro, em caso de acidente? }\end{array}$ \\
\hline 25 & Existe instalação de chuveiro de emergência? \\
\hline 26 & Existe instalação de sistema lavador de olhos? \\
\hline \multicolumn{2}{|r|}{ Substâncias inflamáveis ou explosivas } \\
\hline 27 & $\begin{array}{l}\text { No local de manipulação, almoxarifado e controle de qualidade existem sinalização } \\
\text { indicando que "É proibido fumar" }\end{array}$ \\
\hline 28 & $\begin{array}{l}\text { O local tem instalação elétrica à prova de explosão?Há manutenção preventiva de } \\
\text { todos os equipamentos do laboratório? Existe POP e controle dessas manutenções? }\end{array}$ \\
\hline 29 & $\begin{array}{l}\text { O local é isento de qualquer fonte de calor ou faisca, tais como chapas elétricas } \\
\text { instaladas, a presença de algum equipamento que tenha possibilidade de provocar } \\
\text { faísca ou acender uma chama? }\end{array}$ \\
\hline 30 & $\begin{array}{l}\text { O local é isento de material facilmente combustível como papel, óleos, madeira, } \\
\text { panos, etc? }\end{array}$ \\
\hline 31 & As prateleiras são de difícil combustão? \\
\hline 32 & As paredes, pisos e tetos são resistentes por pelo menos duas horas, ao fogo? \\
\hline 33 & O local é ventilado de forma a evitar acúmulo de gases e vapores? \\
\hline 34 & O local permite fácil acesso de bombeiros para o caso de incêndio? \\
\hline 35 & $\begin{array}{l}\text { Se na empresa existe a presença de substâncias capazes de pegar fogo ou } \\
\text { explodir, estão sendo obedecidos os quesitos propostos na NR23 sobre proteção } \\
\text { contra incêndios? }\end{array}$ \\
\hline 36 & Se no ambiente existem substâncias inflamáveis e explosivas, as roupas dos \\
\hline
\end{tabular}


Silva, F.C.; Rosa, L.P.; Rocha, M.P.; Leite, M.F. Revista Eletrônica de Farmácia Vol. X (2), $01-23,2013$.

\begin{tabular}{|c|c|}
\hline & $\begin{array}{l}\text { trabalhadores, principalmente os aventais (guarda-pós) usados sobre as roupas } \\
\text { comuns, são de algodão, para evitar o acúmulo de cargas eletrostáticas? }\end{array}$ \\
\hline \multicolumn{2}{|c|}{ Substâncias corrosivas } \\
\hline 37 & Os frascos estão armazenados nas prateleiras inferiores? \\
\hline 38 & O almoxarifado é construído com material resistente à gases e vapores corrosivos? \\
\hline 39 & $\begin{array}{l}\text { A geladeira para armazenagem é um geladeira especial, com toda a instalação } \\
\text { elétrica fora do local de armazenagem? }\end{array}$ \\
\hline 40 & $\begin{array}{l}\text { Os frascos estão devidamente tampados, de forma a evitar a evaporação do } \\
\text { produto? }\end{array}$ \\
\hline 41 & $\begin{array}{l}\text { A geladeira é destinada apenas a guardar produtos químicos e é proibido colocar } \\
\text { comidas ou bebidas? }\end{array}$ \\
\hline \multicolumn{2}{|c|}{ Sobre a manipulação de pós } \\
\hline 42 & O trabalho é realizado sob exaustão? \\
\hline 43 & O sistema de exaustão está funcionando bem? \\
\hline 44 & $\begin{array}{l}\text { O sistema de exaustão possui sistema de tratamento dos efluentes de forma a não } \\
\text { contaminar as áreas vizinhas? }\end{array}$ \\
\hline 45 & $\begin{array}{l}\text { O trabalhador está usando equipamento de proteção individual (EPI), neste caso } \\
\text { algum tipo de proteção respiratória, adequada ao tipo de substância que pode } \\
\text { estar no ar? }\end{array}$ \\
\hline 46 & $\begin{array}{l}\text { Esta proteção respiratória está recomendada e sendo acompanhada, por um } \\
\text { Programa de Proteção Respiratória, feito pela empresa? }\end{array}$ \\
\hline \multicolumn{2}{|c|}{ Sobre os trabalhadores } \\
\hline 47 & $\begin{array}{l}\text { Os trabalhadores foram capacitados a trabalhar com os produtos químicos que } \\
\text { estão sendo manuseados?Existem registros? }\end{array}$ \\
\hline 48 & $\begin{array}{l}\text { Estes trabalhadores foram capacitados para realizar os procedimentos de } \\
\text { emergência em caso de acidente?Existem registros? }\end{array}$ \\
\hline 49 & $\begin{array}{l}\text { Se forem feitas avaliações quantitativas, isto é medições com aparelhos, das } \\
\text { quantidades de substâncias no ar, os trabalhadores são informados dos resultados } \\
\text { obtidos? }\end{array}$ \\
\hline 50 & Eles são capacitados a entender estes resultados? \\
\hline 51 & $\begin{array}{l}\text { As roupas de trabalho são trocadas com frequência suficiente para não possibilitar } \\
\text { contaminação do trabalhador? }\end{array}$ \\
\hline 52 & A empresa providencia a lavagem da roupa? \\
\hline 53 & $\begin{array}{l}\text { Os exames médicos a que os trabalhadores são periodicamente submetidos estão } \\
\text { apropriados aos riscos que eles podem estar submetidos no ambiente de trabalho? }\end{array}$ \\
\hline 54 & Se o trabalhador usa EPI, ele foi capacitado para usá-lo? \\
\hline
\end{tabular}


Silva, F.C.; Rosa, L.P.; Rocha, M.P.; Leite, M.F. Revista Eletrônica de Farmácia Vol. X (2), $01-23,2013$.

\begin{tabular}{|l||l||}
\hline 55 & Cada trabalhador tem o seu próprio EPI? \\
\hline 56 & Este EPI é frequentemente limpo ou trocado de acordo com a necessidade? \\
\hline 57 & $\begin{array}{l}\text { Os calçados são fechados, resistentes aos produtos que estão sendo usados e } \\
\text { antiderrapantes? }\end{array}$ \\
\hline 58 & $\begin{array}{l}\text { Se o trabalhador necessita usar luvas, elas são resistentes ao material que vai ser } \\
\text { manuseado? }\end{array}$ \\
\hline
\end{tabular}

Quadro 3: Checklist para avaliação de riscos ergonômicos em farmácia magistral.

\begin{tabular}{|c|c|}
\hline \multicolumn{2}{|r|}{ Barema para riscos ergonômicos } \\
\hline 1 & $\begin{array}{l}\text { Os funcionários que trabalham sentados possuem cadeiras ajustadas para que } \\
\text { seus braços fiquem descansados sobre a mesa de trabalho? (quantos sim e } \\
\text { quantos não?) }\end{array}$ \\
\hline 2 & $\begin{array}{l}\text { Os funcionários que trabalham sentados possuem cadeiras ajustadas para que } \\
\text { suas pernas formem um ângulo de } 90 \text { graus e a planta dos pés totalmente } \\
\text { apoiadas no solo? (Quantos possuem e quantos não?) }\end{array}$ \\
\hline 3 & $\begin{array}{l}\text { As pessoas que trabalham sentadas possuem cadeiras confortáveis quanto ao } \\
\text { encosto das costas? (quantos sim e quantos não?) }\end{array}$ \\
\hline 4 & $\begin{array}{l}\text { Nos ambientes de trabalho (ou setores) existe facilidade em transitar?(quantos sim } \\
\text { e quantos não?) }\end{array}$ \\
\hline 5 & O bebedouro de água fica próximo ao longe dos setores de trabalho? \\
\hline 6 & Os banheiros localizam-se próximos ou longe dos setores de trabalho? \\
\hline 7 & Existe pausas de uma em uma hora para os funcionários movimentarem-se? \\
\hline 8 & $\begin{array}{l}\text { Existe ginástica laboral antes do início das atividades nos diferentes períodos de } \\
\text { funcionamento? }\end{array}$ \\
\hline 9 & $\begin{array}{l}\text { Os funcionários trabalham com calçados apropriados à função no setor e } \\
\text { confortáveis? (Os corretos seriam tênis, sapatos baixos, sandálias baixas não } \\
\text { plásticas, solados antiderrapantes). }\end{array}$ \\
\hline 10 & $\begin{array}{l}\text { Os funcionários recebem instruções sobre cuidados com saúde na empresa } \\
\text { (alimentação, cuidados com peso, realizar algum tipo de exercício físico, doenças } \\
\text { ocupacionais)? }\end{array}$ \\
\hline
\end{tabular}

\section{RESULTADOS}

Baseados no barema construído para realizar o diagnóstico situacional, foi realizado o levantamento dos riscos e observou-se 16 situações de risco físico,
18 situações de risco químico e 7 situações de risco ergonômico. Foram propostas medidas para minimização desses riscos junto com o representante nomeado pela empresa. Assim as medidas acordadas foram adotadas para 
Silva, F.C.; Rosa, L.P.; Rocha, M.P.; Leite, M.F. Revista Eletrônica de Farmácia Vol. X (2), $01-23,2013$.

a construção do manual de sugestões de adequação foram listados Biossegurança na parte inerente à descrição e protocolos de minimização nos quadros 4,5 e 6 e nos tópicos dos riscos. Os resultados bem como as seguintes:

Quadro 4 - Adequação de protocolos de biossegurança - Riscos Físicos

\begin{tabular}{|c|c|c|}
\hline & Diagnóstico situacional & Sugestão de adequação \\
\hline 1 & $\begin{array}{l}\text { Equipamento de proteção } \\
\text { contra incêndio incompleto ou } \\
\text { com falta de sinalização }\end{array}$ & $\begin{array}{l}\text { - Os locais destinados aos extintores } \\
\text { existentes devem ser assinalados por um } \\
\text { círculo vermelho ou por uma seta larga, } \\
\text { vermelha, com bordas amarelas; } \\
\text { - Placa explicativa dos tipos de extintores e } \\
\text { formas adequadas de utilização próxima a } \\
\text { esses; } \\
\text { - Adequar o ambiente com equipamentos } \\
\text { de combate e prevenção a incêndios } \\
\text { adicionais como manta para abafamento } \\
\text { de fogo e sirene de alerta em incêndio; } \\
\text { Anexar em local de fácil visualização uma } \\
\text { ficha de controle de inspeção dos } \\
\text { equipamentos contra incêndios. }\end{array}$ \\
\hline 2 & $\begin{array}{l}\text { Presença de monta-carga } \\
\text { (para deslocamento das } \\
\text { preparações farmacêuticas da } \\
\text { área de manipulação no piso } \\
\text { superior para área de } \\
\text { dispensação no piso térreo) } \\
\text { sem a sinalização adequada, } \\
\text { parapeito com altura } \\
\text { insuficiente, ocasionando risco } \\
\text { de queda e ausência de } \\
\text { delimitação do equipamento } \\
\text { no piso térreo o que leva a } \\
\text { risco de choque direto com os } \\
\text { funcionários que transitam no } \\
\text { local. }\end{array}$ & $\begin{array}{l}\text { - Colocar placas sinalizadoras no local do } \\
\text { risco; } \\
\text { - Delimitar fisicamente a área do monta- } \\
\text { carga no piso térreo; } \\
\text { - Adequar a altura do parapeito no piso } \\
\text { superior. }\end{array}$ \\
\hline 3 & Presença de escada para & - Colocar piso antiderrapante na escada ou \\
\hline
\end{tabular}


Silva, F.C.; Rosa, L.P.; Rocha, M.P.; Leite, M.F. Revista Eletrônica de Farmácia Vol. X (2), $01-23,2013$.

\begin{tabular}{|c|c|c|}
\hline & $\begin{array}{lcr}\text { acesso ao piso } & \text { superior } & \text { sem } \\
\text { corrimão e } & \text { com iluminação } \\
\text { insuficiente. } & \text { Degraus } & \text { e } \\
\text { acidentados } & \text { e } & \text { piso } \\
\text { inadequado. } & \text { Teto } & \text { baixo } \\
\text { oferecendo risco de choque na } \\
\text { região de cabeça. }\end{array}$ & $\begin{array}{l}\text { lixa antiderrapante nos degraus; } \\
\text { - Instalar corrimão; } \\
\text { - Melhorar a iluminação do ambiente; } \\
\text { - Sinalizar altura do teto na escada. }\end{array}$ \\
\hline 4 & $\begin{array}{l}\text { Existência de equipamentos } \\
\text { elétricos na área de lavagem } \\
\text { sem correta sinalização para } \\
\text { evitar choque elétrico. }\end{array}$ & $\begin{array}{l}\text { - Sinalizar adequadamente o risco elétrico; } \\
\text { - Conscientizar os(as) funcionários(as) da } \\
\text { área de lavagem sobre o risco de choque } \\
\text { elétrico ao manusear o equipamento com } \\
\text { as mãos molhadas. }\end{array}$ \\
\hline 5 & $\begin{array}{l}\text { Falta de protocolo operacional } \\
\text { padrão facilmente acessível } \\
\text { frente a vidrarias quebradas }\end{array}$ & 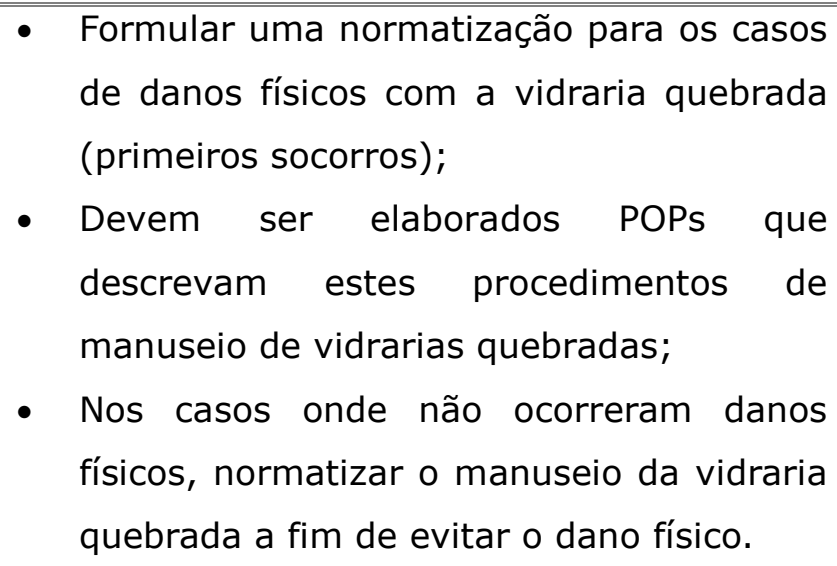 \\
\hline 6 & $\begin{array}{l}\text { Inexistência de saídas de } \\
\text { emergência e rota de fuga } \\
\text { sinalizada nos setores (NR-23) }\end{array}$ & $\begin{array}{l}\text { - Criar rotas de fuga e saídas de } \\
\text { emergência sinalizadas e adequadas aos } \\
\text { diferentes setores. }\end{array}$ \\
\hline 7 & $\begin{array}{l}\text { Tomadas sem sinalização de } \\
\text { voltagem. } \\
\text { sobrecarregadas por ligações } \\
\text { de muitos equipamentos ao } \\
\text { mesmo tempo. }\end{array}$ & $\begin{array}{l}\text { - Sinalizar a voltagem de todas as tomadas; } \\
\text { - Instalação de mais tomadas em locais } \\
\text { onde existem muitos equipamentos } \\
\text { elétricos; } \\
\text { - Desutilização de "T" para evitar } \\
\text { sobrecarga elétrica com risco de curto } \\
\text { circuito e incêndios; } \\
\text { - Desenvolver um planejamento elétrico dos } \\
\text { setores. }\end{array}$ \\
\hline 8 & $\begin{array}{l}\text { Salas de administração com } \\
\text { pouca ventilação }\end{array}$ & - Instalação de climatizadores. \\
\hline 9 & $\begin{array}{l}\text { Porta com retorno automático } \\
\text { sem sinalização }\end{array}$ & $\begin{array}{l}\text { - Sinalizar todos os setores com presença } \\
\text { de portas de retorno automático; }\end{array}$ \\
\hline
\end{tabular}


Silva, F.C.; Rosa, L.P.; Rocha, M.P.; Leite, M.F. Revista Eletrônica de Farmácia Vol. X (2), $01-23,2013$.

\begin{tabular}{|c|c|c|}
\hline 10 & $\begin{array}{lcr}\text { Materiais } & \text { de limpeza } \\
\text { guardados em } & \text { locais } \\
\text { inapropriados (ex. copa) }\end{array}$ & $\begin{array}{l}\text { - Utilização do DML (depósito de material } \\
\text { de limpeza) para armazenamento dos } \\
\text { materiais de limpeza. }\end{array}$ \\
\hline 11 & $\begin{array}{l}\text { Degrau não identificado entre } \\
\text { a copa e o banheiro com risco } \\
\text { de queda }\end{array}$ & $\begin{array}{l}\text { - Sinalizar com fita apropriada o local do } \\
\text { risco. }\end{array}$ \\
\hline 12 & $\begin{array}{l}\text { Falta de sinalização de alta } \\
\text { tensão nas caixas de } \\
\text { disjuntores }\end{array}$ & - Adequar a sinalização. \\
\hline 13 & $\begin{array}{l}\text { Teto da área de lavagem sem } \\
\text { vedação adequada }\end{array}$ & $\begin{array}{l}\text { - Realizar a vedação do local para evitar } \\
\text { pragas e roedores }\end{array}$ \\
\hline 14 & $\begin{array}{l}\text { Trânsito de pessoas dificultado } \\
\text { e com risco de choques entre } \\
\text { pessoas e/ou equipamentos } \\
\text { e/ou móveis na sala de } \\
\text { atendimento telefônico e setor } \\
\text { de atendimento ao público. } \\
\text { Excesso de fiação visível } \\
\text { nessas salas }\end{array}$ & $\begin{array}{l}\text { - Melhorar o planejamento físico e } \\
\text { estrutural desses ambientes ou readequar } \\
\text { o mobiliário e equipamentos a fim de } \\
\text { melhorar a transitação e minimizar os } \\
\text { choques e quedas. }\end{array}$ \\
\hline 15 & $\begin{array}{l}\text { Equipamentos que emitem } \\
\text { grande quantidade de calor } \\
\text { sem sinalização }\end{array}$ & $\begin{array}{l}\text { - Sinalizar os equipamentos que emitem } \\
\text { grande quantidade de calor para evitar } \\
\text { queimaduras e incêndios. }\end{array}$ \\
\hline 16 & $\begin{array}{l}\text { Falta de mensuração dos } \\
\text { ruídos dos equipamentos }\end{array}$ & $\begin{array}{l}\text { - Equipamentos que emitem ruídos acima } \\
\text { do permitido na legislação devem ser } \\
\text { sinalizados; } \\
\text { - Funcionários que trabalham nos setores } \\
\text { onde estão locados equipamentos } \\
\text { ruidosos devem utilizar equipamentos de } \\
\text { proteção individual (EPI) adequados. }\end{array}$ \\
\hline
\end{tabular}

Quadro 5 - Adequação de protocolos de biossegurança - Riscos Químicos

\begin{tabular}{|c|c|c|}
\hline & Diagnóstico situacional & Sugestão de adequação \\
\hline 1 & $\begin{array}{l}\text { Ausência de diagrama de Hommel ou } \\
\text { rotulagem equivalente nos produtos } \\
\text { armazenados no almoxarifado }\end{array}$ & $\begin{array}{l}\text { - Adequar rotulagem específica } \\
\text { dos produtos no almoxarifado. }\end{array}$ \\
\hline 2 & Almoxarifado sem sinalização da presença & - $\quad$ Fixar placas sinalizadoras. \\
\hline
\end{tabular}


Silva, F.C.; Rosa, L.P.; Rocha, M.P.; Leite, M.F. Revista Eletrônica de Farmácia Vol. X (2), $01-23,2013$.

\begin{tabular}{|c|c|c|}
\hline & de produtos químicos & \\
\hline 3 & $\begin{array}{l}\text { Ausência de EPC de emergência e kit de } \\
\text { segurança química no almoxarifado, no } \\
\text { controle de qualidade e área de } \\
\text { manipulação }\end{array}$ & $\begin{array}{l}\text { - Providenciar EPC e kit } \\
\text { específico; } \\
\text { - Providenciar POP contendo } \\
\text { explicações do que fazer em } \\
\text { casos de acidentes com } \\
\text { substâncias químicas; } \\
\text { - Devem ser realizados } \\
\text { treinamentos (registrados em } \\
\text { planilhas) a cerca de } \\
\text { procedimentos emergenciais } \\
\text { em caso de acidentes com } \\
\text { substâncias químicas; } \\
\text { Registrar todos os acidentes } \\
\text { que ocorrerem. }\end{array}$ \\
\hline 4 & $\begin{array}{l}\text { Falta números de telefones de emergência } \\
\text { (atendimento médico, SAMU, corpo de } \\
\text { bombeiros) de fácil visualização no } \\
\text { almoxarifado }\end{array}$ & $\begin{array}{l}\text { - } \begin{array}{l}\text { Providenciar placas com } \\
\text { números de emergência. }\end{array}\end{array}$ \\
\hline 5 & $\begin{array}{l}\text { Ausência de quadro de incompatibilidade } \\
\text { química com base na ficha de informações } \\
\text { de segurança de produtos químicos } \\
\text { (FISQP). }\end{array}$ & 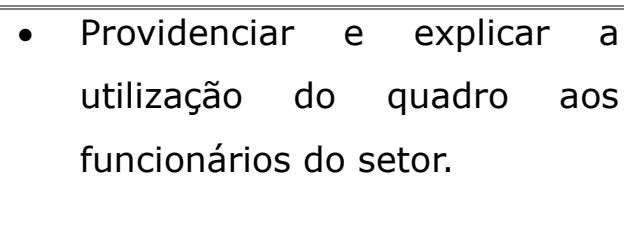 \\
\hline 6 & $\begin{array}{l}\text { Os produtos com incompatibilidade química } \\
\text { não estão armazenados adequadamente }\end{array}$ & $\begin{array}{l}\text { - Segregar os produtos no } \\
\text { almoxarifado com base na } \\
\text { incompatibilidade química. }\end{array}$ \\
\hline 7 & $\begin{array}{l}\text { Ausência de FISQP ou procedimento } \\
\text { operacional padrão (POP) dos produtos } \\
\text { químicos armazenados no almoxarifado }\end{array}$ & $\begin{array}{l}\text { - Providenciar FISQP e POP dos } \\
\text { produtos químicos; } \\
\text { - É necessário que esses dois } \\
\text { documentos estejam } \\
\text { acessíveis. }\end{array}$ \\
\hline 8 & $\begin{array}{l}\text { Prateleiras encontram-se muito altas } \\
\text { dificultando o acesso ao produto e } \\
\text { aumentando o risco de derramamento dos } \\
\text { mesmo (risco químico aos funcionários) }\end{array}$ & $\begin{array}{l}\text { - Diminuir a altura } \\
\text { prateleiras. }\end{array}$ \\
\hline 9 & $\begin{array}{l}\text { Substâncias inflamáveis ou explosivas não } \\
\text { sinalizadas no controle de qualidade }\end{array}$ & - Sinalizar os riscos. \\
\hline
\end{tabular}


Silva, F.C.; Rosa, L.P.; Rocha, M.P.; Leite, M.F. Revista Eletrônica de Farmácia Vol. X (2), 01 - 23, 2013.

\begin{tabular}{|c|c|c|}
\hline 10 & $\begin{array}{l}\text { Grande quantidade de materiais de fácil } \\
\text { combustão na área de controle de } \\
\text { qualidade }\end{array}$ & $\begin{array}{l}\text { - Minimizar a quantidade desses } \\
\text { materiais no setor. }\end{array}$ \\
\hline 11 & $\begin{array}{l}\text { Paredes, pisos e tetos dos diferentes } \\
\text { setores não são resistentes a pelo menos } 2 \\
\text { horas diante de fogo. }\end{array}$ & $\begin{array}{l}\text { - Procurar adequar com base no } \\
\text { auxílio de especialistas; } \\
\text { - Priorizar o setor de controle } \\
\text { de qualidade. }\end{array}$ \\
\hline 12 & $\begin{array}{l}\text { As instalações elétricas não estão de } \\
\text { acordo com a regulamentação NR-19 e } 20 \\
\text { sobre ABNT } \mathrm{n} \text {. P-NB-98 sobre } \\
\text { armazenamento e manuseio de líquidos } \\
\text { inflamáveis e combustíveis }\end{array}$ & - $\quad$ Pro \\
\hline 13 & $\begin{array}{l}\text { Utilização intermitente de máscara } \\
\text { inapropriada no setor de sólido predispondo } \\
\text { os funcionários a inalarem substâncias } \\
\text { químicas. O problema é decorrente do } \\
\text { incômodo pelo uso intensivo da máscara } \\
\text { inapropriada e falta de períodos de } \\
\text { descanso. }\end{array}$ & $\begin{array}{l}\text { - Períodos de descanso } \\
\text { apropriado evitando o uso de } \\
\text { máscara inadequada; }\end{array}$ \\
\hline 14 & $\begin{array}{l}\text { Falta de solicitação de } \\
\text { fornecedor. }\end{array}$ & $\begin{array}{l}\text { - Entrar em contato com } \\
\text { fornecedor dos produtos } \\
\text { químicos para aquisição da } \\
\text { FISQP. }\end{array}$ \\
\hline 15 & 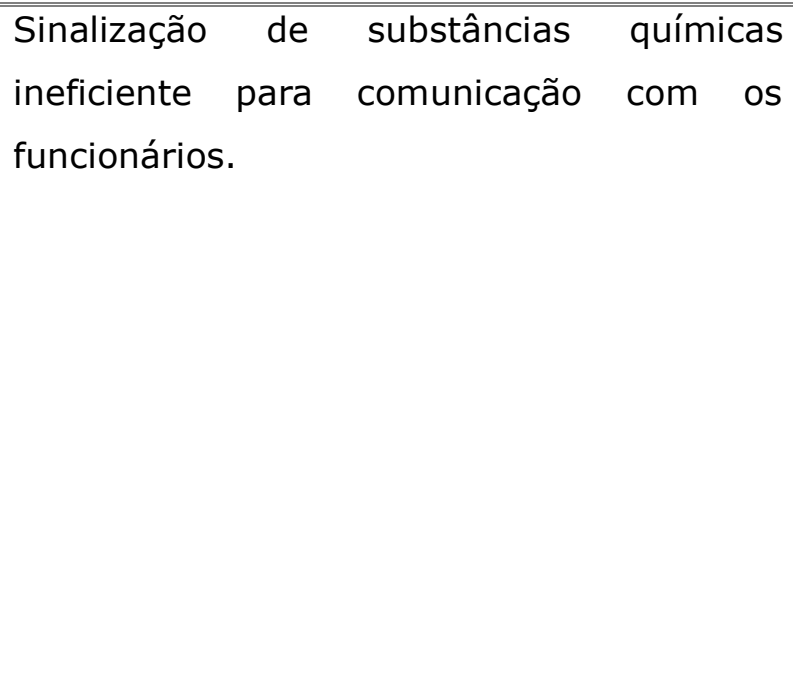 & $\begin{array}{l}\text { - As ausentes devem ser } \\
\text { providenciadas e aquelas } \\
\text { presentes devem ser } \\
\text { periodicamente revisadas; } \\
\text { - } \text { Preparar um programa de } \\
\text { alteração periódica de } \\
\text { sinalização de forma a estar } \\
\text { sempre chamando a atenção } \\
\text { do trabalhador sobre o risco; } \\
\text { Detalhar todo o processo em } \\
\text { POPs. }\end{array}$ \\
\hline 16 & $\begin{array}{l}\text { Lava-olhos não ficam em locais de fácil } \\
\text { acesso e ausência de chuveiro de } \\
\text { emergência. }\end{array}$ & $\begin{array}{llr}\text { - } & \text { Instalar esses } & \text { EPC's } \\
\text { (equipamentos de } & \text { proteção } \\
\text { coletivo) } \quad \text { em } & \text { locais }\end{array}$ \\
\hline
\end{tabular}


Silva, F.C.; Rosa, L.P.; Rocha, M.P.; Leite, M.F. Revista Eletrônica de Farmácia Vol. X (2), $01-23,2013$.

\begin{tabular}{|c|c|c|}
\hline & & estratégicos e de fácil acesso. \\
\hline 17 & $\begin{array}{l}\text { Não são realizadas medições das } \\
\text { quantidades de substâncias químicas no ar } \\
\text { dos setores onde desenvolve-se } \\
\text { manipulação dos produtos químicos. Os } \\
\text { trabalhadores não são informados sobre } \\
\text { essas quantidades. }\end{array}$ & $\begin{array}{l}\text { - } \text { Realizar medições periódicas e } \\
\text { repassar os dados obtidos } \\
\text { para os funcionários; } \\
\text { - Detalhar tais medições, } \\
\text { procedimentos e periodicidade } \\
\text { em POPs; } \\
\text { - Criar planilhas para controle } \\
\text { dos resultados das medições } \\
\text { periódicas. }\end{array}$ \\
\hline 18 & $\begin{array}{l}\text { Material de confecção dos jalecos é } \\
\text { inadequado }\end{array}$ & 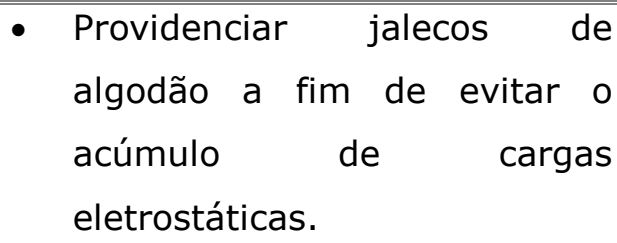 \\
\hline
\end{tabular}

Quadro 6-Adequação de protocolos de biossegurança - Riscos Ergonômicos

\begin{tabular}{|c|c|c|}
\hline & Diagnóstico situacional & Sugestão de adequação \\
\hline 1 & $\begin{array}{l}\text { No laboratório de semi-sólidos trabalham três } \\
\text { funcionários durante a manhã e dois à tarde, } \\
\text { existe apenas uma cadeira ergonômica. }\end{array}$ & 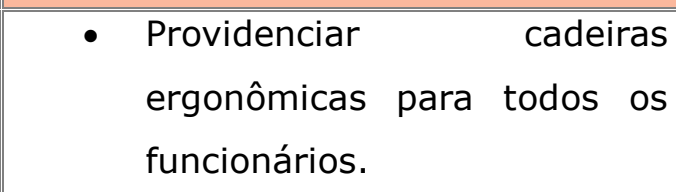 \\
\hline 2 & $\begin{array}{l}\text { Em todos os setores somente existem uma } \\
\text { pausa em cada turno de } 15 \text { minutos para } \\
\text { descanso. }\end{array}$ & $\begin{array}{l}\text { - Adotar pausas de } 10 \text { minutos } \\
\text { em média de uma em uma } \\
\text { hora para descanso dos } \\
\text { funcionários e práticas de } \\
\text { alongamento. }\end{array}$ \\
\hline 3 & $\begin{array}{l}\text { Especialmente nas salas de telefonia e } \\
\text { recepção existe grande dificuldade de } \\
\text { transito com presença de fios, objetos e } \\
\text { móveis obstruindo a passagem. Na sala de } \\
\text { telefonia trabalham dois funcionários e o } \\
\text { ambiente não possui espaço suficiente. }\end{array}$ & 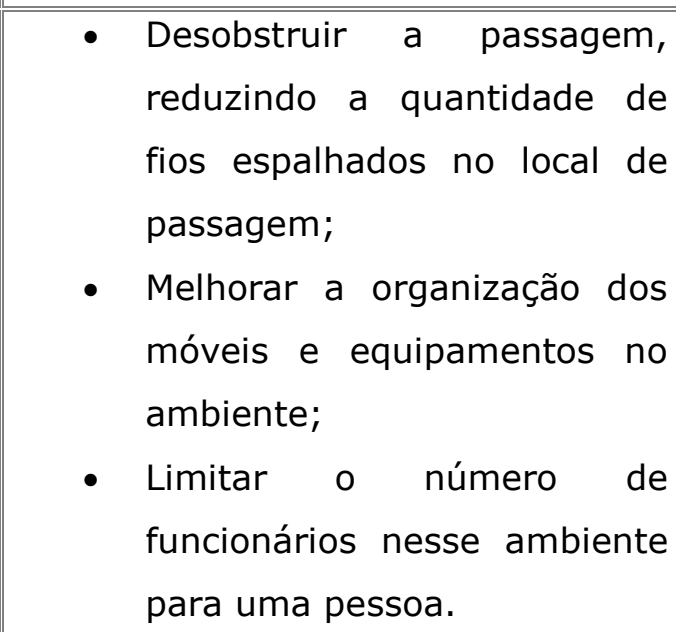 \\
\hline 4 & $\begin{array}{l}\text { No segundo piso, somente existe um } \\
\text { bebedouro que fica na sala de lavagem de }\end{array}$ & $\begin{array}{l}\text { - Providenciar bebedouro na } \\
\text { sala de telefonia ou área de }\end{array}$ \\
\hline
\end{tabular}


Silva, F.C.; Rosa, L.P.; Rocha, M.P.; Leite, M.F. Revista Eletrônica de Farmácia Vol. X (2), $01-23,2013$.

\begin{tabular}{|c|c|c|}
\hline & agnóstico situacional & Sugestão de adequação \\
\hline & $\begin{array}{l}\text { instrumentos. Os funcionários de outros } \\
\text { setores fora da área de manipulação deve se } \\
\text { paramentar para atravessar a barreira "sujo- } \\
\text { limpo" e então ter acesso ao bebedouro. } \\
\text { Muitos preferem o bebedouro do primeiro } \\
\text { piso. }\end{array}$ & $\begin{array}{l}\text { circulação no segundo piso } \\
\text { em uma área mais } \\
\text { estratégica para minimizar o } \\
\text { estresse físico e favorecer a } \\
\text { ingestão de água pelos } \\
\text { funcionários. }\end{array}$ \\
\hline 5 & $\begin{array}{l}\text { Algumas funcionárias geralmente trabalham } \\
\text { com sandálias e sapatos com salto } \\
\text { inadequados (ultrapassa } 5 \mathrm{~cm} \text {, finos, bicos } \\
\text { finos, antiderrapante). Acima disso, há uma } \\
\text { alteração de postura porque a pessoa precisa } \\
\text { manter o equilíbrio na parte anterior do pé. }\end{array}$ & 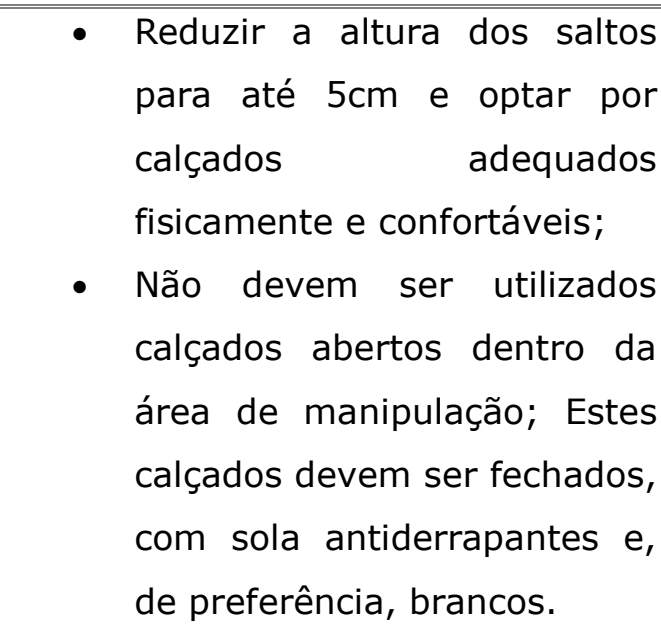 \\
\hline 6 & $\begin{array}{l}\text { Os setores de semi-sólidos e almoxarifado } \\
\text { possuem prateleiras com altura acima do } \\
\text { alcançado pelos funcionários. }\end{array}$ & $\begin{array}{l}\text { - } \text { Reorganização dos espaços } \\
\text { existentes para que se possa } \\
\text { retirar os materiais das } \\
\text { prateleiras mais altas e } \\
\text { recolocá-los em prateleiras } \\
\text { mais baixas. }\end{array}$ \\
\hline 7 & $\begin{array}{l}\text { Os funcionários que exercem a manipulação } \\
\text { de cápsulas estão sujeitos a tensões elevadas } \\
\text { e possíveis complicações relacionadas à má } \\
\text { postura, repetição de movimentos e } \\
\text { impossibilidade de mudança de posição, o } \\
\text { que é agravado pelo uso de máscaras } \\
\text { durante todo o período de trabalho. } \\
\text { (exigência da RDC 67/2007) Os mesmos } \\
\text { relatam constantes dores osteomusculares na } \\
\text { região de cabeça e pescoço (local onde } \\
\text { existem muitas estruturas anatômicas } \\
\text { nobres). }\end{array}$ & 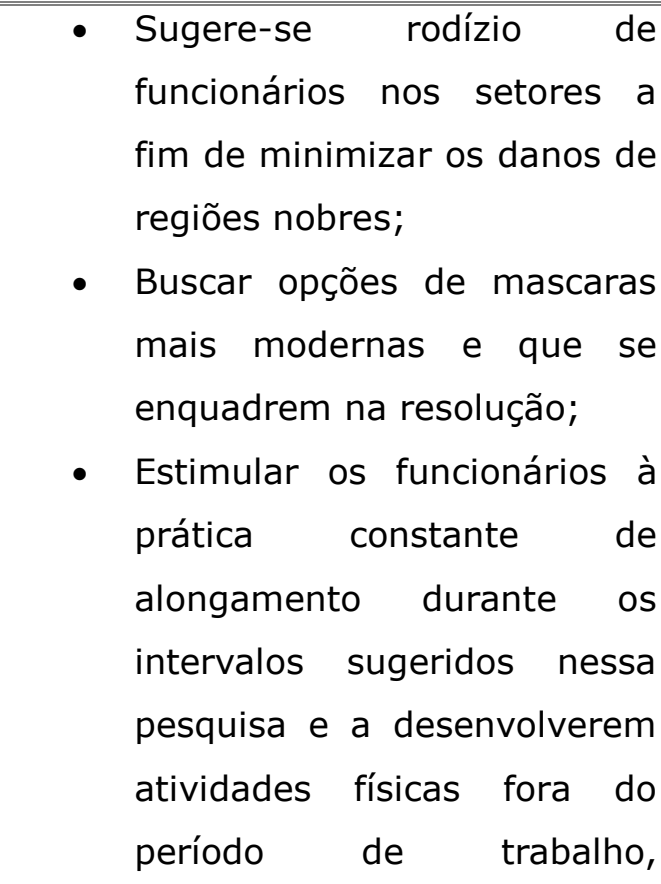 \\
\hline
\end{tabular}


Silva, F.C.; Rosa, L.P.; Rocha, M.P.; Leite, M.F. Revista Eletrônica de Farmácia Vol. X (2), $01-23,2013$.

\begin{tabular}{|l||l|}
\hline Diagnóstico situacional & Sugestão de adequação \\
\hline \hline & principalmente atividades \\
como natação, hidroginástica \\
e pilates (devido ao foco \\
regional).
\end{tabular}

ELABORAÇÃO DO MANUAL DE BIOSSEGURANÇA

Após a realização do diagnóstico situacional baseado nos aspectos levantados no barema construído para essa finalidade, foi elaborado um manual contendo informações sobre os riscos físicos, químicos, biológicos e ergonômicos aos quais os funcionários da empresa estariam expostos. Este manual seguiu a regulamentação da RDC $67 / 2007$ e Normas regulamentadoras (NRs) no que se refere às normas de biossegurança e minimização de riscos.

$\mathrm{Na}$ elaboração desse manual foram utilizados outros manuais de biossegurança, livros técnicos da área, normas regulamentadoras e legislações pertinentes, buscando reunir as informações mais relevantes para os funcionários sobre os riscos aos quais poderiam estar expostos, em linguagem compatível com o público alvo de maneira atrativa através de fotos, ilustrações, figuras, entre outros. O manual foi construído juntamente com os representantes da empresa e apresentado em aula expositiva para os funcionários conhecerem o conteúdo do manual e saberem como consultá-lo. Foi sugerido à empresa disponibilizar uma versão digital e impressa do manual aos funcionários ou um link de acesso rápido no site da empresa.

\section{CONFECÇÃO DO MAPA DE RISCOS \\ Com os dados coletados na} empresa foi possível confeccionar um mapa de riscos. Para isso foi utilizada a planta baixa do piso superior e térreo disponibilizada pela empresa. A mesma foi adaptada e então realizada a marcação, através das cores especifica de cada risco em todos os ambientes dos setores da farmácia como visualizado abaixo: 
Silva, F.C.; Rosa, L.P.; Rocha, M.P.; Leite, M.F. Revista Eletrônica de Farmácia Vol. X (2), $01-23,2013$.

Figura 1: Mapa de riscos de uma farmácia magistral do interior da Bahia

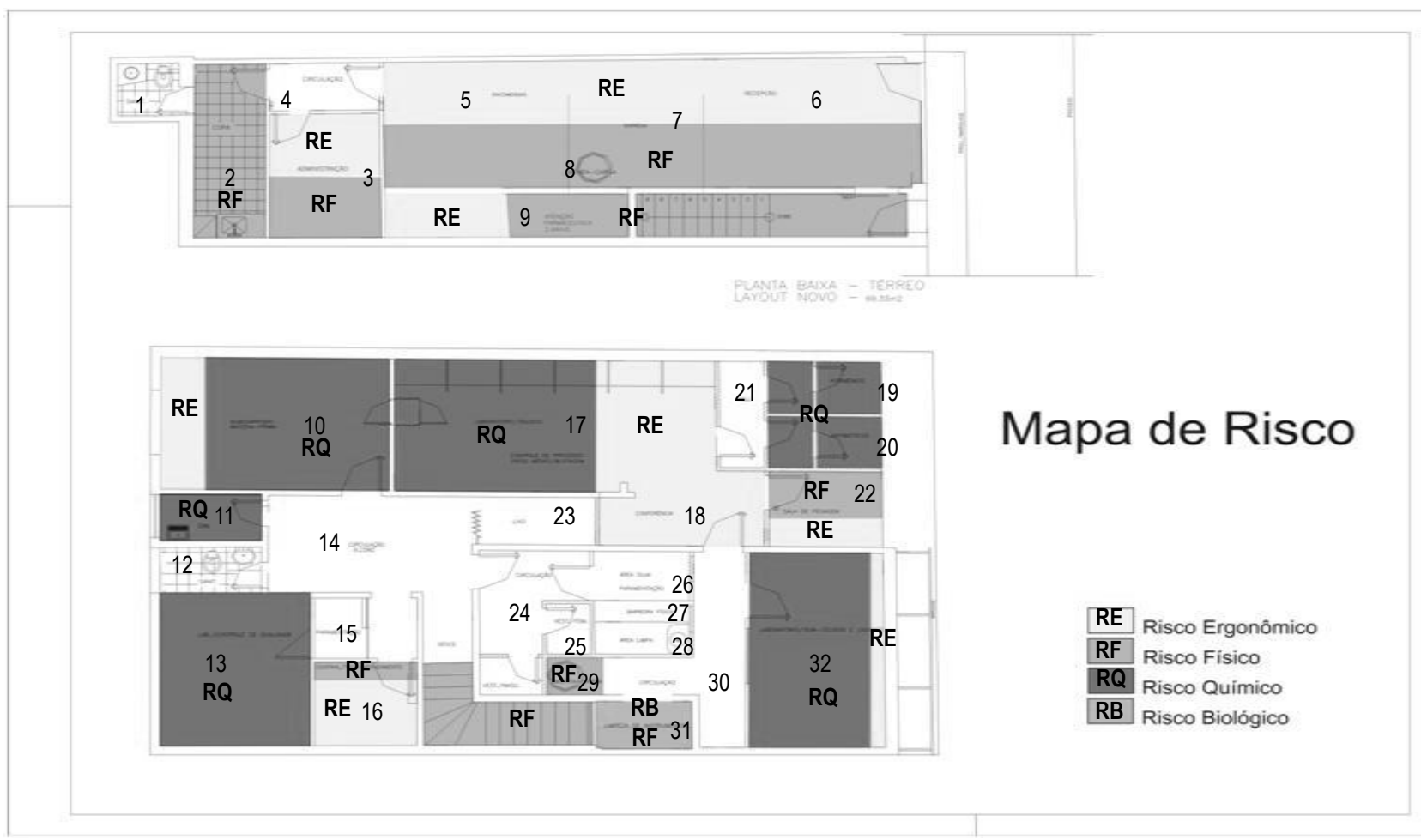

1 - sanitário; 2 - copa; 3 - administração; 4 - circulação; 5 - encomendas/ entrega de fármacos; 6 - recepção; 7 entrega; 8 - monta-carga; 9 -atenção farmacêutica; 10 - almoxarifado/ matéria-prima; 11 - DML; 12 - sanitário; 13 - laboratório controle de qualidade; 14 - circulação; 15 - paramentação; 16 - central tele-atendimento; 17 laboratório sólidos; 18 - conferência; 19 - hormônios; 20 - antibióticos; 21 - hall; 22 - sala de pesagem; 23 - lixo; 24 - circulação; 25 - vestuário masculino; 26 - área suja paramentação; 27 - barreira física; 28 - área limpa; 29 monta-carga; 30 - circulação; 31 - limpeza instrumentos; 32 - laboratório semi-sólidos e líquidos. RE - risco ergonômico; RF - risco físico; RQ - risco químico; RB - risco biológico

TRABALHOS DE INFORMAÇÃO, CONSCIENTIZAÇÃO E MOTIVAÇÃO DOS FUNCIONÁRIOS PARA MEDIDAS DE BIOSSEGURANÇA.

Neste estudo também foi evidenciado a necessidade de trabalhar junto aos funcionários aspectos instrutivos, informativos e de motivação sobre os riscos e a biossegurança, ou seja, a adoção de postura e a prática de medidas preventivas para a minimização dos riscos enfatizados na empresa. No intuito de trabalhar esse aspecto com os funcionários da empresa, foram realizadas palestras sobre "Primeiros
Socorros e Combate a incêndios", ambas com apoio do Grupamento de Bombeiros militares da cidade, além de "Contaminantes Particulados e Uso de Cabines de Segurança Biológica Classe I na Farmácia Magistral" ministrada pela graduanda do curso de Farmácia, autora desse artigo, Marisol Porto Rocha.

\section{CAMPANHA DE IMUNIZAÇÃO \\ Com a evidenciação da} necessidade de práticas que minimizem o risco biológico na empresa, percebeuse que seria necessário realizar um trabalho de imunização dos funcionários. 
Silva, F.C.; Rosa, L.P.; Rocha, M.P.; Leite, M.F. Revista Eletrônica de Farmácia Vol. X (2), $01-23,2013$.

Além disso, o processo de imunização é uma medida preventiva às doenças ocupacionais e uma medida de promoção de saúde que está de acordo com a RDC n. 67 de 2007, no seu capítulo sobre Saúde, Higiene, Vestuário e Conduta. O processo de imunização também é uma medida de precauções padrão adotada universalmente para pessoas que trabalham na área da saúde e está de acordo com a NR 32. Para realização do procedimento de imunização na empresa, primeiramente foi solicitado apoio do Setor de Vigilância Epidemiológica da Secretaria de Saúde da cidade, para disponibilização das doses das vacinas contra Hepatite B, Tétano/ Difteria, Rubéola/ Sarampo e Gripe Sazonal/ H1N1.

\section{DISCUSSAO}

Avaliando os aspectos legais, a empresa cumpre com as principais exigências da RDC 67/2007, como a contenção segregada com sistema exaustão/ventilação apropriado para manipulação de antibióticos, hormônios e citotóxicos; uso de EPIs; implantação do Programa de Controle Médico de Saúde Ocupacional (PCMSO). No entanto, a preocupação dos farmacêuticos magistrais não deverá se concentrar apenas em cumprir as exigências legais. Há também uma necessidade de natureza ética e também do próprio negócio em proteger a saúde dos seus funcionários. Quando um deles adoece, o custo em tempo e dinheiro para solução deste problema será maior que a adoção de medidas preventivas e pró-ativas de proteção. Além disso, os efeitos adversos à saúde do funcionário podem ser irreversíveis, ocasionando o seu afastamento definitivo do trabalho e perda do investimento realizado pela empresa no seu treinamento. O risco de despesas em decorrência de indenizações por ações trabalhistas e de responsabilidade judicial também deve ser considerado. Dessa forma, mesmo a empresa cumprindo as principais exigências legais da RDC 67/2007, existem alguns problemas na farmácia e em seu processo de produção que ainda faltam ser resolvidos ou adaptados. São pontos que oferecem, de alguma forma, risco às pessoas que lá trabalham ou mesmo transitam no local de recepção aos clientes. Apesar de não ter ocorrido acidentes graves até então, 0 fato de haver elementos potencialmente causadores para tal, é algo preocupante. Como evidenciado, nos quadros anteriores, os riscos químicos foram os mais evidentes. A empresa manipula diversos produtos farmacêuticos, entre eles, uma quantidade considerável de fármacos com risco de toxicidade. Destacam-se os antibióticos, hormônios esteroidais e peptídicos além de anticonvulsivantes. Muitos deles podem apresentar um ou mais perfis diferentes de toxicidade como genotoxicidade; carcinogenicidade; teratogenicidade ou 
Silva, F.C.; Rosa, L.P.; Rocha, M.P.; Leite, M.F. Revista Eletrônica de Farmácia Vol. X (2), $01-23,2013$.

toxicidade reprodutiva (ex. causa infertilidade em estudos com animais ou pacientes tratados) ou promovem sérias manifestações tóxicas orgânicas em baixas doses evidenciadas em experimentos com animais ou em pacientes tratados $\left({ }^{7,8}\right)$. Nesse caso, a adoção de medida para minimização dos riscos que merece maior atenção é a utilização de EPIs apropriados para a manipulação destes medicamentos, como a utilização da máscara de carvão ativado, o qual age como filtro químico para partículas de até 0,2 micra. Esta máscara deve ser descartável e proteger principalmente 0 nariz e a boca. Máscaras com filtro HEPA também se mostram adequadas. As máscaras cirúrgicas ocasionalmente utilizadas pelos funcionários da empresa não oferecem proteção adequada, já que não possuem o poder de retenção de aerossóis $\left({ }^{7,8}\right)$. Foi relevante a verificação da presença de capela de exaustão de gases, já que o sistema de exaustão é necessário quando se trata de substâncias que causem danos a saúde de forma preocupante.

A observação da rotulagem adequada nos produtos químicos, como o Diagrama de Hommel é importante para identificação dos agentes químicos quanto aos riscos à saúde, a inflamabilidade, a reatividade e aos riscos específicos que porventura o produto venha a apresentar. Essas indicações também são essenciais para um correto combate às situações de incêndio.

Vale ressaltar que, apesar do barema conter um número menor de quesitos de avaliação para riscos ergonômicos, os problemas detectados na farmácia geram um grande impacto sobre os demais riscos identificados. Isso pode ser observado pela utilização intermitente de máscara inapropriada no setor de sólidos, predispondo os funcionários a inalarem substâncias químicas, situação esta identificada no quadro de riscos químicos. O problema, no entanto, é decorrente do incômodo pelo uso intensivo da máscara apropriada e falta de períodos de descanso caracterizando um importante risco ergonômico. Cabe ressaltar que a empresa deve disponibilizar máscaras mais confortáveis e os funcionários devem utilizá-las sempre.

Devido à empresa não possuir laboratório de controle de qualidade microbiológico ou manusear microrganismos e fluídos biológicos, a situação avaliada para tal risco foi a condição de imunização dos funcionários por levantamento das carteiras de vacinação, sendo notificado que $90 \%$ dos funcionários não apresentavam a imunização atualizada ou nunca haviam tomado algumas vacinas básicas para profissionais da área da saúde como Tétano, Rubéola e Hepatite $B\left({ }^{9}\right)$. Como resposta a esses resultados, foi realizada uma campanha de imunização na empresa com aplicação das vacinas 
Silva, F.C.; Rosa, L.P.; Rocha, M.P.; Leite, M.F. Revista Eletrônica de Farmácia Vol. X (2), $01-23,2013$.

citadas.

Além da imunização dos funcionários, são importantes medidas de controle de infecção a correta sanitização das instalações e equipamentos, uma adequada higienização das mãos e antebraços pelos funcionários do laboratório e uma rigorosa sanitização das embalagens das matérias-primas que passam da área comum da farmácia para o laboratório de manipulação.

Quanto ao mapa de riscos, devido a uma exigência normativa, o mesmo foi elaborado neste projeto apenas com intuito de motivação e conscientização dos funcionários a cerca do risco. O mapa de riscos elaborado neste estudo, apenas qualitativo, foi incluído na manual de biossegurança e não tem caráter oficial. De acordo com a Norma regulamentadora no 5 "CIPA" Portaria no 8, de 23/02/1999 - Ministério do Trabalho o mapa de riscos só poderá ser fixado depois de discutido e aprovado pela CIPA (Comissão Interna de Prevenção de Acidentes) $\left({ }^{10}\right)$.

As palestras realizadas com a colaboração do Corpo de Bombeiros do município foram solicitadas em função da necessidade de efetuar-se treinamento e aperfeiçoamento dos funcionários sobre medidas básicas de primeiros socorros e prevenção de incêndio e principalmente com intuito de promover a conscientização e motivação a cerca desses aspectos da biossegurança. A proposta obteve boa adesão e interesse por parte dos funcionários, o que foi verificado pela participação e questionamentos levantados durante as palestras. Da mesma forma, na palestra sobre "Contaminantes Particulados e Uso de Cabines de Segurança Biológica Classe I na Farmácia Magistral" foi verificada uma ótima adesão e participação de todos na empresa e pertinente à necessidade da empresa, devido à exposição dos funcionários a diversos produtos com alto potencial tóxico explicitado anteriormente.

\section{CONCLUSÃO}

Com base no trabalho executado foi possível concluir que:

a) Os funcionários da farmácia magistral estão expostos a algum tipo de risco de natureza química, física, biológica ou ergonômica;

b) As sugestões de adequação propostas com base no diagnóstico dos riscos encontrados podem ser colocadas em prática, mas a maior parte dessas adequações depende da viabilidade do proprietário da Empresa, motivo pelo qual não foi possível adequar todos os protocolos de biossegurança e sim sugerir adequações;

c) A construção do checklist se mostrou se mostrou viável na sua incorporação total ou parcialmente no processo de auditoria interna periódica realizada pelas farmácias magistrais para o estrito 
Silva, F.C.; Rosa, L.P.; Rocha, M.P.; Leite, M.F. Revista Eletrônica de Farmácia Vol. X (2), $01-23,2013$.

cumprimento e eficácia das
medidas preventivas adotadas.
d) Tanto as palestras como a
campanha de imunização foram
importantes para motivar os
funcionários em relação às
questões de biossegurança e de
saúde do trabalhador;
e) Houve uma interação entre o
trabalho proposto nesse estudo e
os funcionários da empresa
através das visitações que
despertaram a curiosidade e
interesse no trabalho, das
palestras de orientação,
informação e conscientização
sobre o assunto, através do
sucesso da participação dos
funcionários na campanha de

imunização e através da participação na palestra de apresentação dos resultados desse trabalho e entrega do manual desenvolvido para a empresa;

Trabalhos como este devem ser realizados constantemente para que os funcionários fiquem sempre motivados na execução das atitudes acerca de biossegurança, sintam que a empresa está zelando pela sua saúde e passem a desempenhar suas funções com mais responsabilidade e satisfação, o que será benéfico para a empresa, para os próprios funcionários e para os pacientes que utilizam os produtos da farmácia magistral.

\section{REFERÊNCIAS BLIBLIOGRÁFICAS}

1. Borges FMR, Ribeiro NK. A tipologia de solução de riscos aplicada numa farmácia de manipulação. In: Anais do XXVII Encontro Nacional de Engenharia de Produção; 2007; Foz do Iguaçu, Paraná, Brasil.

2. Delgado MG. Curso de Direito do Trabalho. $11^{\text {a }}$ ed. São Paulo: Editora LTr. 2012. 1488p.

3. RDC n० 67, de 8 de outubro de 2007 - Dispõe sobre Regulamento técnico sobre as Boas Práticas de Manipulação de Preparações Magistrais para Uso Humano em farmácias. Diário Oficial da União (Brasília). 2007.

4. Soares LJP. Os impactos financeiros dos acidentes do trabalho no orçamento brasileiro: uma alternativa política e pedagógica para redução dos gastos [monography]. Brasília: Especialização em Orçamento Público - Instituto Serzedello Correa; 2008. 66p. 
Silva, F.C.; Rosa, L.P.; Rocha, M.P.; Leite, M.F. Revista Eletrônica de Farmácia Vol. X (2), $01-23,2013$.

5. Cezarino LO, Campomar MC. Vantagem competitiva para micro, pequenas e médias empresas: clusters e APLs. E\&G Economia Gest. 2006;6(12):143-158.

6. Freitas NBB, Arcuri ASA. Riscos devido às substâncias químicas. $1^{\text {a }}$ ed. São Paulo: INST - Instituto Nacional de Saúde no Trabalho - CUT. 2000. 40p.

7. Moroni P, Pierini F, Cazzaniga R, Nava C, Fortuna R, Petazzi A. Osserviazioni su una casistica di lavoratori professionalmente esposti a corticosteroidi [Observationson a case load of workers occupationally exposed to corticosteroids]. Med Lav. 1988;79:142149.

8. Ferreira AO, Brandão M. Guia Prático de Farmácia Magistral. 4a ed. São Paulo: Pharmabooks; 2011. 1438p.

9. Garcia LP, Facchini LA. Vacinação contra a hepatite B entre trabalhadores da atenção básica à saúde. Cad. Saúde Pública. 2008;24(5):1130-1140.

10. Ministério do Trabalho; Portaria n. ${ }^{\circ} 3.214$, de 08 de Junho de 1978 - Aprova as Normas Regulamentadoras - NR - do Capítulo V, Título II, da Consolidação das Leis do Trabalho, relativas a Segurança e Medicina do Trabalho. Brasília (Brasil): Ministério do Trabalho; 1978.

\section{AGÊNCIA DE FOMENTO}

Bolsas de apoio ao desenvolvimento tecnológico às Micro e Pequenas Empresas - BITEC, IEL-BA/ CNPq 2009. 